\title{
The impact of age and sex on healthcare expenditure of households in Bangladesh
}

\author{
Abdur Razzaque Sarker ${ }^{1 *}$, Rashidul Alam Mahumud ${ }^{1,2}$, Marufa Sultana', Sayem Ahmed ${ }^{1}$, Wahid Ahmed \\ and Jahangir AM Khan ${ }^{1,2,3}$
}

\begin{abstract}
The impact of age and sex on health care expenditure has recently become one of the major concerns in many developing countries like Bangladesh. Age and sex differences in the use of health care services can be substantial at several stages of life which are reflected in overall healthcare expenditure.

We examined the impact of age and sex of the population on overall healthcare expenditure of households in Bangladesh.

A total of 10,705 populations who spent for receiving any type of healthcare services were analyzed from Bangladesh Household Income and Expenditure Survey data, 2010. Sex and age group were considered as childhood (0-19), young adult (20-39), middle-aged adult (40-64), senior aged (65-84) and old senior aged (84+) for the entire analysis. Total healthcare expenditure was derived by considering direct cost such as physician's fee, cost of medicine, diagnostic, transportation, tips and informal payment etc. Indirect and intangible cost was not considered in the analysis.

The study found that overall health care expenditure of male (US\$ 11.5) is higher than female (US\$11.2) while this is higher for female (US\$ 14.2) than male (US\$ 11.3) in the reproductive age. The highest health expenditure was observed in male (US\$ 69.7) of age 65-69 years and in female (US\$23.4) of age 75-79 years. The cost for hospitalization was significantly higher (US \$23.7) for female than male (US\$21.1). Overall health expenditure was observed to be significantly higher in elderly than younger people.

These findings provide an experimental framework for the continuing inquiry of equity in the allocation of health care expenditure between male and female at different age, which suggest current health care system in Bangladesh place a significant financial strain on the elderly population.
\end{abstract}

Keywords: Health care expenditure; Reproductive age; Sex; Bangladesh

\section{Introduction}

The impact of age and sex on health care expenditure has recently become one of the major concerns in many developing countries like Bangladesh (Meng and Yeo 2005). According to latest health bulletin of ministry of health and family welfare of Bangladesh, the estimated total population was 154.8 million (MOHFW 2013). The demographic structure is changing faster and the population pyramid is wider at the bottom than the top and narrows slightly at the youngest age group (BDHS 2011).

\footnotetext{
* Correspondence: arazzaque@icddrb.org

${ }^{1}$ Health Economics and Financing Research Group, Center for Equity and Health Systems, International Centre for Diarrhoeal Disease Research, Bangladesh (icddr,b), Dhaka, Bangladesh

Full list of author information is available at the end of the article
}

The life expectancy at birth for both sexes is increasing from 65 to 69 years according to latest health bulletin (MOHFW 2013). This demographic nature have attracted considerable attention from policy makers, healthcare managerial level and public health expertise since it will exert on rising healthcare costs. However, it is also important that the age and sex specific utilization pattern varies among the different age groups over time. The utilization of health care services normally depends on particular health problem that reflected in overall healthcare expenditure. Health care expenditure is strongly age dependent, an experience that takes on increasing significance as the childhood generation ages consequently faster change of ageing (Alemayehu and Warner 2004). Also the health care expenditures are lowest for children after the first 
year of life, rise slowly throughout adult life, and increase exponentially after 50 years age (Meerding et al. 1998). In earlier study found that the health care expenditures for the elderly people are about four to five times in their early teens and the senior oldest group (85+) consumes three times as much health care per person as those 65-74, and twice as much as those 75-84 (Bradford and Max 1996; Fuchs 1998).

Previous studies examined that age of the population strongly influenced the health care expenditures (Gerdtham et al. 1992; Khan et al. 2004), and also established the relationship between age and health care expenditure. However, the age-specific health care utilization changes over the different age groups (Seshamani and Gray 2002). Further, other studies reported that health care utilization was more in female than male (Hibbard and Pope 1983; Verbrugge and Wingard 1987; Waldron 1983). In general, female have a tendency to use preventive and diagnostic services more frequently than male, but the emergency services utilization is more in male Gómez (2002). The Goodman's model found that age effect the individual's health care expenditure, where health was considered as human capital that depreciates with age (Grossman 1972). However, it was also examined that aged people invest more to support the health resources supply (Folland et al. 2003). Again, few studies suggested that clinicians treat younger patients differently than they treat older patients, adjusting for disease severity and also for patient preferences (James et al. 2008; Schwarzkopf et al. 2012; Leena et al. 2007). The objective of the study was to focus whether and to what extent age and sex of the population have impact on overall healthcare expenditure of households in Bangladesh. Since this paper focused mainly on healthcare expenditure attributed for individuals, and hence, was based on household level data.

\section{Methods}

The present study derived from Household Income and Expenditure Survey-2010. A total of 10,705 populations who spent for receiving any healthcare services were analyzed and thus who didn't spend on healthcare services was excluded (HIES 2011). Like earlier study, sex and age group were considered as childhood (0-19), young adult (20-39), middle-aged adult (40-64), senior aged (65-84) and old senior aged (84+) for the entire analysis (Alemayehu and Warner 2004). The sampling technique, survey design, survey instruments, measuring system and quality control have been described elsewhere (HIES 2011). Total healthcare expenditure was derived by summing up direct medical cost and direct non-medical cost. Direct medical costs included hospital outpatient fees, medicines, admission or registration fees, physician fees, diagnostic fees, and any other associated medical supplies. The direct non-medical costs include transportation and conveyance, lodging, tips and other associated costs. Indirect costs like income or productivity losses were not captured in this study. However, like other study, intangible costs that is the costs related to suffering and grief, were also excluded from this analysis (Sarker et al. 2013). Data were entered into Microsoft Excel 2007 and statistical analysis was performed using STATA-12. ANOVA was performed to examine the health care expenditure among the human life stages. Results were presented as an average, standard deviations with mean differences, in US\$ applying the exchange rate (US\$ $1=69 \mathrm{BDT}$ ) during the data collection year (2010). To estimate the relationship of healthcare expenditure (HE) to age and sex, the following interactive model was used as suggested earlier study (Diehr et al. 1999).

$$
H E=a+b(\operatorname{sex})+c(\text { age })+d(\text { age })(\operatorname{sex})+\epsilon
$$

\section{Results}

A total of 10,705 population including male (47.05\%) and female (52.95\%) were enrolled in this study. The highest health expenditure was observed in case of male (US\$ 69.7) with 65-69 years of age and in case of female (US\$ 23.4) with 75-79 years of age (Table 1). However, healthcare expenditure was higher (US\$ 14.1) in female than man (US\$ 11.7) in the reproductive period (Figure 1). Considering the under five age group, healthcare spending was significantly higher in male child (US\$7.5) compared to female (US\$ 5.7). The overall health care expenditure of male (US\$ 11.5) was consistently higher than female (US\$ 11.2).

\section{Healthcare expenditure across human life stages}

In healthcare expenditure across human life stage was presented in Table 2. The average healthcare expenditure was higher for male at the senior aged (US\$ 34.9) followed by old senior age (US\$ 30.6). However, in female, the highest healthcare expenditure was observed in middle aged adult (US\$ 14.6) followed by young adult (US\$ 14.5). ANOVA result showed significant difference health care expenditures for all the human life stages $(\mathrm{P}<0.00)$.

\section{Distribution of healthcare expenditure considering sex}

The distribution of healthcare expenditure considering sex revealed that medicine cost (US\$ 7.51) was the highest cost driver followed by diagnostic test (US\$ 1.16) in case of male (Table 3). Similarly, in case of female, medicine cost (US\$ 6.45) was also the highest cost driver. However, in case of tips, which considered often as informal payment was relatively higher in female (US\$ 0.29) than male (US\$ 0.06) which also depicted the higher utilization of maternity services by female. 
Table 1 Household average health expenditure in US\$ (mean \pm SD) across age groups

\begin{tabular}{cccc}
\hline Age & Male & Female & Mean difference (95\% Cl of mean difference) \\
\hline Up to 4 & $7.52 \pm 35.66$ & $5.72 \pm 16.74$ & $1.80^{* *}(0.78-2.54)$ \\
$5-9$ & $5.06 \pm 10.31$ & $4.05 \pm 8.25$ & $1.01^{*}(0.87-1.98)$ \\
$10-14$ & $5.57 \pm 16.04$ & $5.51 \pm 21.15$ & $0.06(-0.05-0.59)$ \\
$15-19$ & $7.16 \pm 11.84$ & $12.45 \pm 40.91$ & $-5.29^{* * *}(-7.87-0.076)$ \\
$20-24$ & $10.03 \pm 20.40$ & $11.77 \pm 26.93$ & $-1.74^{*}(-2.54-1.50)$ \\
$25-29$ & $13.07 \pm 33.90$ & $18.05 \pm 104.97$ & $-4.98^{* * *}(-5.65-0.05)$ \\
$30-34$ & $12.82 \pm 30.35$ & $13.98 \pm 39.91$ & $-1.16^{*}(-2.13-0.87)$ \\
$35-39$ & $11.66 \pm 37.63$ & $13.83 \pm 37.90$ & $-2.16^{* *}(-3.42-1.54)$ \\
$40-44$ & $11.80 \pm 23.45$ & $11.26 \pm 28.39$ & $0.54(0.041-1.25)$ \\
$45-49$ & $15.49 \pm 54.78$ & $17.43 \pm 68.05$ & $-1.94^{*}(-2.54-2.65)$ \\
$50-54$ & $21.47 \pm 81.42$ & $15.48 \pm 36.28$ & $5.99^{* *}(1.43-7.54)$ \\
$55-59$ & $10.83 \pm 17.24$ & $17.13 \pm 38.98$ & $-6.31^{* * *}(-7.86-1.04)$ \\
$60-64$ & $12.14 \pm 23.93$ & $11.94 \pm 19.24$ & $0.20(-0.32-0.76)$ \\
$65-69$ & $69.72 \pm 651.40$ & $13.47 \pm 40.73$ & $56.25^{* * *}(45.65-67.98)$ \\
$70-74$ & $13.68 \pm 25.95$ & $9.42 \pm 11.93$ & $4.26^{* *}(3.76-6.98)$ \\
$75-79$ & $9.91 \pm 16.70$ & $23.47 \pm 102.80$ & $-13.56^{* * *}(-15.98-(-10.76))$ \\
$80+$ & $28.57 \pm 77.51$ & $9.08 \pm 13.60$ & $19.49^{* * *}(13.87-26.98)$ \\
Total & $11.51 \pm 108.12$ & $11.20 \pm 44.85$ & $0.30(-0.05-1.23)$ \\
\hline
\end{tabular}

NB: ***, ** and * denote 1\%, 5\% and 10\% significance level respectively, 1 US\$ =69 BDT in 2010.

\section{Relationship of healthcare expenditure to age and sex}

Table 4 showed the relationship between healthcare expenditure on age and sex. Healthcare expenditure is significantly associated with age, which means that healthcare expenditures were clearly age dependent; an aging population will imply increasing total healthcare expenditures. However, no such relation was established considering sex.

\section{Discussion}

The two major findings of the study are that, the average healthcare expenditure is higher in male than female

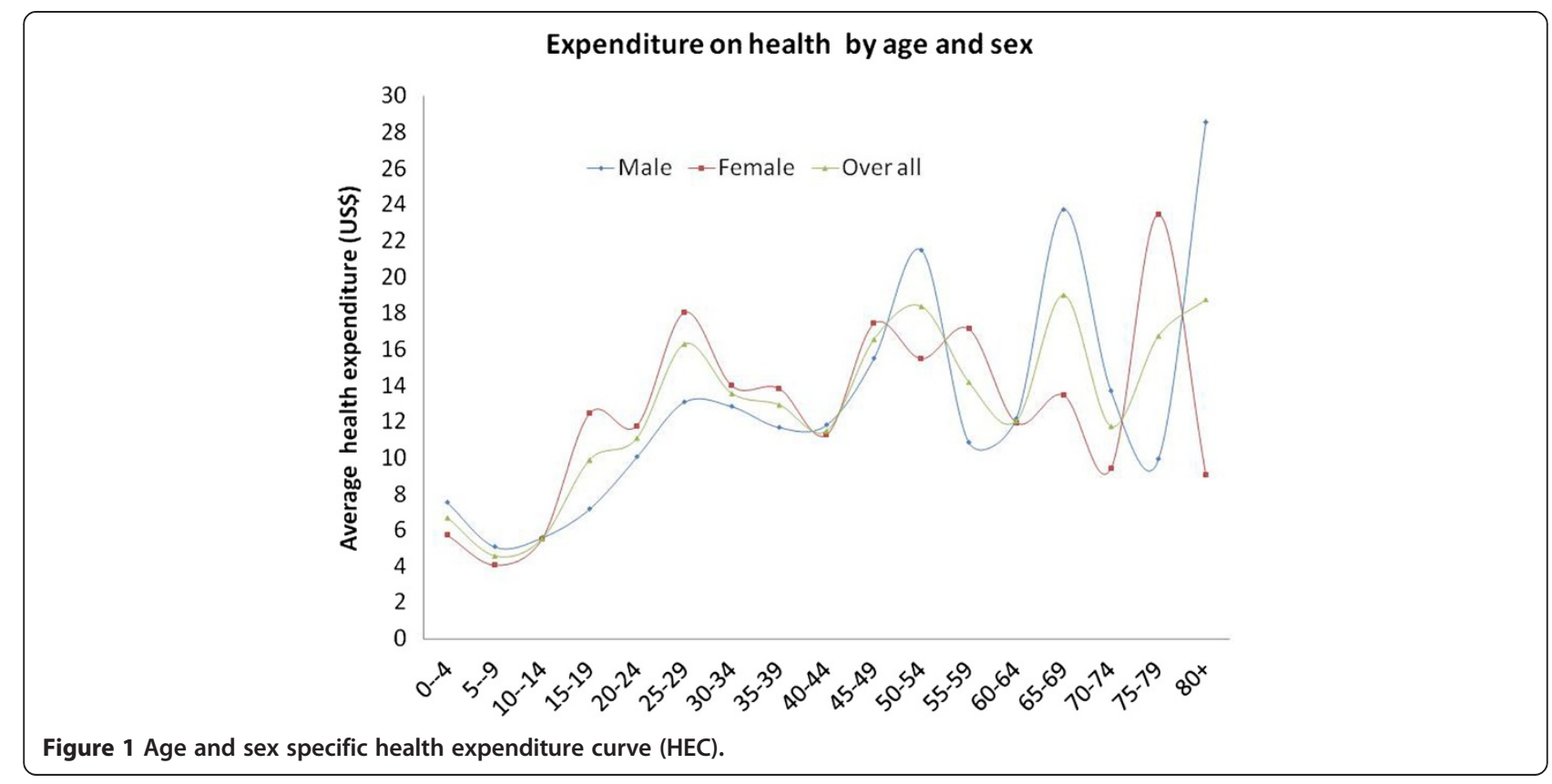


Table 2 Household average healthcare expenditure in US\$ (mean \pm SD) across human life stage

\begin{tabular}{lccc}
\hline Human life stage & Male & Female & Mean diff (95\% Cl) \\
\hline Childhood (0-19 years) & $6.40 \pm 24.20$ & $6.33 \pm 22.30$ & $0.07(-0.03-1.01)$ \\
Young adult (20-39 years) & $11.87 \pm 31.47$ & $14.53 \pm 62.62$ & $-2.8^{*}(-3.21-0.056)$ \\
Middle-aged adult (40-64 years) & $14.60 \pm 48.81$ & $14.67 \pm 43.86$ & $-0.07(-1.26-0.098)$ \\
Senior aged (65 - 84 years) & $34.90 \pm 392.52$ & $13.09 \pm 51.98$ & $21.81^{* *}(15.87-24.87)$ \\
Old senior aged (85 and above) & $30.59 \pm 87.65$ & $12.52 \pm 16.64$ & $18.07^{* * *}(16.45-23.65)$ \\
Total & $11.51 \pm 108.12$ & $11.20 \pm 44.85$ & $0.31(0.051-0.986)$ \\
\hline
\end{tabular}

NB: *** and ${ }^{*}$ denote $1 \%$ and $10 \%$ significance level respectively.

and elderly population expend more than younger people. It was also found that no age and sex specific pattern on healthcare expenditure exists in Bangladesh (Figure 1) which also similar with the findings of other studies (Gómez 2002; Ladwig et al. 2000). A number of studies observed that sex and reproductive biology and mortality to male-female differences in the use of health care services, which also reflected in the current study (Mustard et al. 1998; Roos et al. 1987). Considering female, it was seen that healthcare expenditure curve was rising sharply at age range 70-74 and also declining sharply aged over 79 years. However, some other studies also found that most of the elderly female aged 60 years and above received medical service more frequently than male (Áurea et al. 2006; Fernández-Mayoralas et al. 2000; Mutran and Ferraro 1988). Furthermore, policy makers in many countries faces the challenge of this overpressure that elderly populations utilize more health care thus increase in health care expenditure which also confront in this study (Barer et al. 1989).

The results of this study are consistent with findings from a range of health care systems describing higher expenditures for medicine cost and diagnostic care for male than female. Considering the different types of sex

Table 3 Distribution of average healthcare expenditure in US\$ by sex

\begin{tabular}{lccc}
\hline Particulates & Male & Female & $\begin{array}{c}\text { Mean diff (95\% Cl of } \\
\text { mean diff) }\end{array}$ \\
\hline Physician fee & 0.77 & 0.8 & $-0.03(-0.67$ to 0.75$)$ \\
Hospital cost & 0.79 & 0.8 & $-0.01(-0.72$ to 0.54$)$ \\
Medicine cost & 7.51 & 6.45 & $1.06^{* *}(0.43$ to 1.89$)$ \\
Diagnostic test & 1.16 & 1.39 & $-0.23(-0.89$ to 0.43$)$ \\
Conveyance cost & 0.72 & 0.63 & $0.09(-0.10$ to 0.28$)$ \\
Tips cost & 0.06 & 0.29 & $-0.23(-1.47$ to 1.01$)$ \\
Other costs & 0.5 & 0.39 & $0.11(-0.17$ to 0.39$)$ \\
Maternity clinic cost & - & 0.23 & - \\
Maternity midwife cost & - & 0.03 & - \\
Maternity others & - & 0.21 & - \\
Total & 11.51 & 11.2 & $0.30(-0.06$ to 0.66$)$ \\
\hline
\end{tabular}

NB: ** denote $5 \%$ significance level. specific healthcare services (Table 3) medicine cost is significantly higher in male than female. In childhood period, health care expenditure for male is slightly higher than female which showed the similar findings of other study in Bangladesh (Sarker et al. 2013) and this paper addressed some inequality in case of medicine cost that it provided less frequent in male than female.

This study examined more closely the influence of healthcare expenditures in Bangladesh which help for policy makers plotting health service utilization and healthcare expenditure patterns against age and sex. Nevertheless, there are two important changeable things need to recognized for health policy makers, firstly, the age and sexspecific utilization patterns among different age groups over time and secondly, the life expectancy of the population which can provide accurate projections of future healthcare expenditure of the country. However, these results provide an experimental framework for the continuing inquiry of equity to provide equal care for both male and female at different stages of human life. Future research needed in this area to provide the effect of age and sex on healthcare demand in Bangladesh.

The study has some limitations. There may be some recall bias as data were collected after receiving the health services. Furthermore, this survey data (HIES2010) mentions nothing about proxy interviews; in cases where children and elderly people were unable to respond to the interviews, some proxy respondents may have been interviewed. However, we do not have the full access of any datasets of HIES-2000 or 2005, so we were not able to measure inequality across age groups and gender.

Table 4 Relationship of healthcare expenditure in US\$ to age and sex

\begin{tabular}{|c|c|c|c|c|}
\hline \multirow[t]{2}{*}{ Variables } & \multirow[t]{2}{*}{ Coefficients } & \multirow{2}{*}{$\begin{array}{l}\text { Std. } \\
\text { err. }\end{array}$} & \multicolumn{2}{|c|}{$(95 \% \mathrm{Cl})$} \\
\hline & & & Lower & Upper \\
\hline Constant & $1.53^{* * *}$ & 3.96 & -6.24 & 9.29 \\
\hline Age & $0.40^{* * *}$ & 0.11 & 0.17 & 0.62 \\
\hline Sex & 2.62 & 2.52 & -2.33 & 7.57 \\
\hline Age $\times$ sex & -0.12 & 0.07 & -0.26 & 0.02 \\
\hline
\end{tabular}

NB: *** denote $1 \%$ significance level. 


\section{Competing interests}

The authors declare that they have no competing interests.

\section{Authors' contributions}

ARS and RAM designed and planned the study. The study was coordinated by ARS, RAM, MS, SA, WA and JAMK. ARS, RAM, MS assisted in the analysis. Interpretation of the data was conducted by ARS, RAM and JAMK. The manuscript was drafted by ARS, RAM, MS, SA, WA and JAMK. All authors critically reviewed and approved the final manuscript.

\section{Acknowledgments}

icddr,b is thankful to the Governments of Australia, Bangladesh, Canada, Sweden and the UK for providing core/unrestricted support. The authors would also like to the thank health economics and financing research groups for their comments on an earlier draft of the manuscript.

\section{Author details}

${ }^{1}$ Health Economics and Financing Research Group, Center for Equity and Health Systems, International Centre for Diarrhoeal Disease Research, Bangladesh (icddr,b), Dhaka, Bangladesh. ${ }^{2}$ Centre for Excellence in Universal Health Coverage at icddr,b and James P Grant School of Public Health, BRAC University, Dhaka, Bangladesh. ${ }^{3}$ Adjunct Faculty, Health Economics Unit, Department of Learning, Informatics, Management and Ethics, Karolinska Institutet, Stockholm, Sweden.

\section{Received: 21 May 2014 Accepted: 6 August 2014}

\section{Published: 14 August 2014}

\section{References}

Alemayehu B, Warner KE (2004) The Lifetime Distribution of Health Care Costs. Health Serv Res 39(3):627-42

Áurea R, Pilar GA, José R, Fernando R (2006) Gender differences in the utilization of health-care services among the older adult population of Spain. BMC Public Health 6:155

Barer M, Pulcins I, Evans R, Hartsman C, Lumas J, Anderson G (1989) Trends in use of medical srvice es by the elderly in British Columbia. Camn Med Assoc J 141:39-45

BDHS (2011) Bangladesh Demographic and Health Survey. National Institute of Population Research and Training. Dhaka, Bangladesh

Bradford DF, Max DA (1996) "Implicit Budget Deficits: The Case of a Mandated Shift to Community-Rated Health Insurance." NBER working paper Cambridge, MA: National Bureau of Economic Research, vol 5514. Cambridge

Diehr P, Yanez D, Ash A, Hornbrook M, Lin D (1999) Methods for analyzing health care utilization and costs. Annu Rev Public Health 20:125-44

Fernández-Mayoralas G, Rodríguez V, Rojo F (2000) Health services accessibility among Spanish elderly. Soc Sci Med 50:17-26

Folland S, Goodman AC, Stano M (2003) The Economics of Health and Health Care,4th Edition. Prentice-Hall, New Jersey

Fuchs V (1998) Provide, Provide: The Economics of Aging NBER working paper no 6642. National Bureau of Economic Research. MA, Cambridge

Gerdtham UG, Sogaard J, Jonsson B, Andersson F (1992) A pooled cross-section analysis of the health care expenditures of the OECD countries. Dev Health Econ Public Policy 1:287-310

Gómez G (2002) Género, equidad y acceso a los servicios de salud: una aproximación empírica. Rev Panam Salud Publica 11:327-334

Grossman M (1972) On the concept of health capital and the demand for health. J Polit Econ 80:223-255

Hibbard J, Pope C (1983) Gender roles, illness orientation and use of medical services. Soc Sci Med 17:129-37

HIES (2011) Household income \& expenditure survey-2010. In: BBS (ed) HIES. Bangladesh bureau of statistic, Dhaka, Bangladesh

James E, Rohrer NR, Steven A (2008) IIIness severity and total visits in family medicine. J Eval Clin Pract 14(1):65-69

Khan J, Gerdtham UG, Jansson B (2004) Effects of macroeconomic trends on social security spending due to sickness and disability. Am J Public Health 94(11):2004-9

Ladwig K, Marten-Mittag B, Formanek B, Dammann G (2000) Gender differences of symptom reporting and medical health care utilization in the German population. Eur J Epidemio 16:511-518

Leena F, Pekka R, Anja N, Jani R, Marja (2007) Health and social service use among old people in the last 2 years of life. Eur J Ageing 4(3):145-154
Meerding WJ, Bonneux L, Polder JJ, Koopmanschap MA, van der Maas PJ (1998) Demographic and Epidemiological Determinants of Healthcare Costs in Netherlands: Cost of Illness Study. Br Med J 317(7251):111-15

Meng X, Yeo C (2005) Ageing and health-care expenditure in urban China. http://people.anu.edu.au/xin.meng/age-healthexp.pdf. Access: May, 2014

MOHFW (2013) Health Bulletin 2013. Directorate General of Health Services (DGHS), Dhaka, Bangladesh, http://www.dghs.gov.bd/images/docs/ Other_Publication/HB\%202013\%20final\%20-\%20Full\%20version\%201March14. pdf. Access: May 2014

Mustard CA, Kaufert P, Kozyrskyj A, Mayer T (1998) Sex Differences in the Use of Health Care Services. N Engl J Med 338(23):1678-1683, doi:10.1056/NEJM199806043382307

Mutran E, Ferraro K (1988) Medical need and use of services among older men and women. J Gerontol 43:162-171

Roos N, Montgomery P, Roos L (1987) Health care utilization in the years prior to death. Milbank Q 65:231-54

Sarker AR, Islam Z, Khan IA, Saha A, Chowdhury F, Khan Al, Qadri F, Khan JAM (2013) Cost of illness for cholera in a high risk urban area in Bangladesh: an analysis from household perspective. BMC Infect Dis 13(1):518, doi:10.1186/ 1471-2334-13-518

Schwarzkopf L, Menn P, Leidl R, Wunder S, Mehlig H, Marx P, Graessel E, Holle R (2012) Excess costs of dementia disorders and the role of age and genderan analysis of German health and long-term care insurance claims data. BMC Health Serv Res 12(1):165

Seshamani M, Gray A (2002) The impact of ageing on expenditures in the National Health service. Age Ageing 31:287-94

Verbrugge L, Wingard D (1987) Sex differentials in health and mortality. Woman Health 12:103-45

Waldron I (1983) Sex differences in illness incidence, prognosis and mortality: issues and evidence. Soc Sci Med 17:1107-23

\section{doi:10.1186/2193-1801-3-435}

Cite this article as: Sarker et al:: The impact of age and sex on healthcare expenditure of households in Bangladesh. SpringerPlus 2014 3:435.

\section{Submit your manuscript to a SpringerOpen ${ }^{\odot}$ journal and benefit from:}

- Convenient online submission

Rigorous peer review

- Immediate publication on acceptance

- Open access: articles freely available online

- High visibility within the field

- Retaining the copyright to your article

Submit your next manuscript at $>$ springeropen.com 